\title{
Fatigue crack growth in thin aluminium alloy sheets under loading sequences with periodic overloads
}

\author{
L.P. Borrego ${ }^{\mathrm{a}, *}$, J.M. Costa ${ }^{\mathrm{b}}$, J.M. Ferreira ${ }^{\mathrm{b}}$ \\ ${ }^{a}$ Department of Mechanical Engineering, Instituto Superior de Engenharia de Coimbra-ISEC, \\ Rua Pedro Nunes, Quinta da Nora, 3030-199 Coimbra, Portugal \\ ${ }^{\mathrm{b}}$ Department of Mechanical Engineering, Universidade de Coimbra, Polo II, \\ Pinhal de Marrocos, 3030-201 Coimbra, Portugal
}

Received 2 March 2004; accepted 5 November 2004

\begin{abstract}
This study analyses the fatigue crack growth behaviour in thin AlMgSi1-T6 aluminium alloy sheets under several loading sequences containing periodic overloads. The observed fatigue crack growth behaviour is compared to constant amplitude loading and discussed in terms of type of loading sequence, intermediate baseline cycles and stress ratio. The crack closure parameter $U$ was obtained for periodic single overload tests and compared with the crack growth transients. Crack retardation increases with overload periodicity and decreases with stress ratio increase. Higher crack growth retardation was observed under loading sequences with decreasing load levels in comparison to increasing ones as well as under loading sequences with extended periodicity. In spite of some discrepancy, attributed to the quick change of the closure levels, it is clear that plasticity-induced crack closure plays an important role on the load interaction effects observed in this aluminium alloy. (C) 2005 Elsevier Ltd. All rights reserved.
\end{abstract}

Keywords: Aluminium; Thin walled-sections; Periodic overloads; Crack growth; Crack closure

\section{Introduction}

It is widely known that in the last decade's aluminium alloys have been more and more used in the production industry, mainly in ground transport systems. The 6xxx series alloys are commonly use in thin-walled structural applications due to the fact of presenting

\footnotetext{
* Corresponding author. Tel.: +351 962560101; fax: +351 239790331.

E-mail address: borrego@isec.pt (L.P. Borrego).
} 
relatively high strength, good corrosion resistance and high toughness combined with good formability and weldability.

For many fatigue critical parts of structures, vehicles and machines, fatigue crack propagation under service conditions generally involves random or variable amplitude, rather than constant amplitude loading conditions. When a fatigue crack is subjected to these load variations accelerations and/or retardations in crack growth rate can occur [1,2]. Thus, an accurate prediction of fatigue life requires an adequate evaluation of these load interaction effects.

The majority of the work carried out in this field has been on the effects of single peak tensile overloads [3-7] simply because this type of loading can lead to significant load interaction effects. In contrast, other variable amplitude loading sequences have not yet been exhaustively investigated. Among them, intermittent single or block overloads [8-12] are experienced by a large number of engineering components.

Several mechanisms have been proposed to explain crack growth retardation following peak tensile overloads, which include models based on residual stress, crack closure, crack tip blunting, strain hardening, crack branching and reversed yielding. However, the precise micromechanisms responsible for the load interaction effects are not fully understood.

In recent work, the authors observed that the plasticity-induced crack closure phenomenon could generally explain the crack growth behaviour following single peak overloads under both load control mode [6] and constant $\Delta K$ conditions [7]. The present work intends to analyse the fatigue crack growth due to several loading sequences containing periodic single overloads and to clarify if the observed behaviour can also be correlated with the crack closure phenomenon. Additionally, the crack growth behaviour under periodic block of overloads and periodic three-level loading sequences will also be analysed.

\section{Experimental procedure}

This research was conduced using the AlMgSi1 (6082) aluminium alloy with a T6 heat treatment. The T6 heat treatment corresponds to a conversion of heat-treatable material to the age-hardened condition by solution treatment, quenching and artificial age-hardening. The alloy chemical composition and mechanical properties are shown in Tables 1 and 2, respectively.

The fatigue tests were conducted using Middle-Tension, $\mathrm{M}(\mathrm{T})$, specimens with a thickness of $3 \mathrm{~mm}$, in agreement with the ASTM E647 standard [13]. The specimens were obtained in the longitudinal transverse (LT) direction from a laminated plate. Fig. 1 shows the major dimensions of the samples used in the tests. The notch preparation was made by

Table 1

Chemical composition of AlMgSi1-T6 aluminium alloy (wt\%)

\begin{tabular}{lllllllll}
\hline $\mathrm{Si}$ & $\mathrm{Mg}$ & $\mathrm{Mn}$ & $\mathrm{Fe}$ & $\mathrm{Cr}$ & $\mathrm{Cu}$ & $\mathrm{Zn}$ & $\mathrm{Ti}$ & Other \\
\hline 1.05 & 0.8 & 0.68 & 0.26 & 0.01 & 0.04 & 0.02 & 0.01 & 0.05 \\
\hline
\end{tabular}


Table 2

Mechanical properties of AlMgSi1-T6 aluminium alloy

\begin{tabular}{ll}
\hline Tensile strength, $\sigma_{\mathrm{UTS}}(\mathrm{MPa})$ & $300 \pm 2.5$ \\
Yield strength, $\sigma_{\mathrm{YS}}(\mathrm{MPa})$ & $245 \pm 2.7$ \\
Elongation, $\varepsilon_{\mathrm{r}}(\%)$ & 9 \\
Cyclic hardening exponent, $n^{\prime}$ & 0.064 \\
Cyclic hardening coefficient, $K^{\prime}(\mathrm{MPa})$ & 443 \\
Fatigue strength exponent, $b$ & -0.0695 \\
Fatigue strength coefficient, $\sigma_{\mathrm{f}}^{\prime}(\mathrm{MPa})$ & 485 \\
Fatigue ductility exponent, $c$ & -0.827 \\
Fatigue ductility coefficient, $\varepsilon_{\mathrm{f}}^{\prime}$ & 0.773
\end{tabular}

electrical-discharge machining. After that, the specimen surfaces were polished mechanically.

All experiments were performed in a servohydraulic, closed-loop mechanical test machine with $100 \mathrm{kN}$ load capacity, interfaced to a computer for machine control and data acquisition. All tests were conducted in air, at room temperature and with a frequency of $20 \mathrm{~Hz}$. The specimens were clamped by hydraulic grips. The crack length was measured using the d.c. potential drop method. At specific intervals the crack length was also measured using a travelling microscope $(45 \times)$ with a resolution of $10 \mu \mathrm{m}$ in order to verify the potential drop method measures. Collection of data was initiated after achieving an initial crack length $2 a_{0}$ of approximately $12 \mathrm{~mm}$.

Several loading sequences with overloads were analysed, namely, periodic single overloads, periodic multiple overloads and periodic three-level loading sequences. The tests were performed under load control mode by previously programming the loading sequences presented in Tables 3-5. The influence of the different loading sequences was investigated in the Paris regime, at $R=0.05$ and 0.25 for intermittent single overloads and at $R=0.05$ for the other loading sequences. The crack growth rates were determined by the secant method [13].

Periodic overloading was started after the crack had grew to a crack length corresponding to $\Delta K=6 \mathrm{MPa} \mathrm{m}^{1 / 2}$. The overload ratio OLR was kept constant at 1.5 which was defined as:

$$
\mathrm{OLR}=\frac{\Delta K_{\mathrm{OL}}}{\Delta K_{\mathrm{BL}}}=\frac{K_{\mathrm{OL}}-K_{\min }}{K_{\max }-K_{\min }}
$$

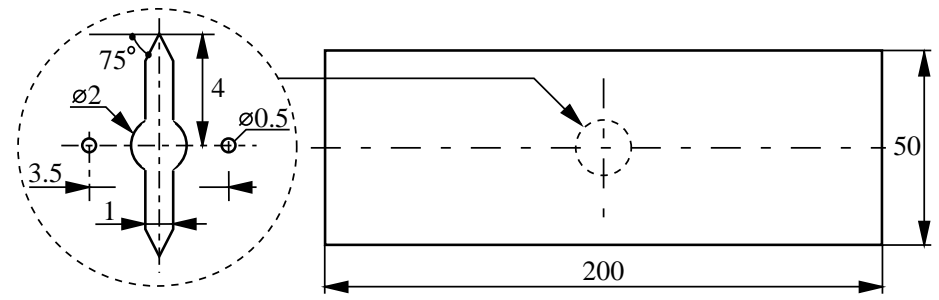

Fig. 1. Geometry of the $\mathrm{M}(\mathrm{T})$ specimen used in this work (dimensions in $\mathrm{mm}$ ). 
Table 3

Periodic single overloads

\begin{tabular}{lll}
\hline Loading sequence & $R(-)$ & Period, $n_{\mathrm{BL}}$ (cycles) \\
\hline & & 10 \\
& 0.05 & 100 \\
& & 1000 \\
& 0.40 & 10,000 \\
\hline
\end{tabular}

$\Delta P_{\mathrm{BL}}=5510 \mathrm{~N}(\Delta \sigma=36.73 \mathrm{MPa})$.

Table 4

Periodic multiple overloads

\begin{tabular}{|c|c|c|c|c|}
\hline \multicolumn{2}{|c|}{ Loading sequence } & \multirow{2}{*}{$\begin{array}{l}N_{1} \text { (cycles) } \\
1000\end{array}$} & \multirow{2}{*}{$\frac{N_{2} \text { (cycles) }}{250}$} & \multirow{2}{*}{$\frac{N_{2} / N_{1}(-)}{0.25}$} \\
\hline \multirow{3}{*}{$\mathrm{N}_{1}$} & \multirow{2}{*}{$1.5 \mathrm{P}_{\max }$} & & & \\
\hline & & 1000 & 500 & 0.50 \\
\hline & $\mathrm{P}_{\max }$ & 200 & 100 & 0.50 \\
\hline
\end{tabular}

$P_{\min }=225 N, P_{\max }=4500 N\left(\sigma_{\min }=1.5 \mathrm{MPa}, \sigma_{\max }=30 \mathrm{MPa}\right)$.

where $K_{\max }, K_{\min }$, and $K_{\mathrm{OL}}$ are the maximum, minimum and peak overload intensity factors, respectively. Therefore, each overload was applied with $50 \%$ increase in load, respectively, to the baseline loading range.

During the periodic single overload tests the load-displacement behaviour was monitored at specific intervals using a pin microgauge. The gauge pins were placed in the two drilled holes of $0.5 \mathrm{~mm}$ diameter located above and below the centre of the notch (Fig. 1). The distance between these holes was $3.5 \mathrm{~mm}$. In order to collect as many loaddisplacement data points as possible during a particular cycle the frequency was reduced to Table 5

Periodic three-level load sequences

\begin{tabular}{|c|c|c|c|}
\hline Loading sequence & $N_{1}$ (cycles) & $N_{2}$ (cycles) & $N_{3}$ (cycles) \\
\hline 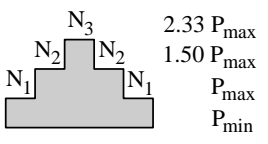 & 500 & 1000 & 1000 \\
\hline 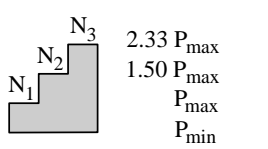 & $\begin{array}{r}1000 \\
10,000\end{array}$ & $\begin{array}{r}1000 \\
10,000\end{array}$ & $\begin{array}{r}1000 \\
10,000\end{array}$ \\
\hline \begin{tabular}{|rr}
$\mathrm{N}_{3}$ & $2.33 \mathrm{P}_{\max }$ \\
$\mathrm{N}_{2}$ & $1.50 \mathrm{P}_{\max }$ \\
$\mathrm{N}_{1}$ & $\mathrm{P}_{\max }$ \\
& $\mathrm{P}_{\min }$
\end{tabular} & 1000 & 1000 & 1000 \\
\hline
\end{tabular}

$P_{\min }=150 N, P_{\max }=3000 N\left(\sigma_{\min }=1 \mathrm{MPa}, \sigma_{\max }=20 \mathrm{MPa}\right)$. 
$0.5 \mathrm{~Hz}$. Noise on the strain gauge output was reduced by passing the signal through a $1 \mathrm{~Hz}$ low-pass mathematical filter.

From the load-displacement records, variations of the opening load, $P_{\mathrm{op}}$, were derived using the technique known as maximisation of the correlation coefficient [14]. This technique involves taking the upper $10 \%$ of the $P-\varepsilon$ data and calculating the least squares correlation coefficient. The next data pair is then added and the correlation coefficient is again computed. This procedure is repeated for the whole data set. The point at which the correlation coefficient reaches a maximum could then be defined as $P_{\mathrm{op}}$.

The fraction of the load cycle for which the crack remains fully open, parameter $U$, was calculated by the following equation:

$$
U=\frac{P_{\max }-P_{\mathrm{op}}}{P_{\max }-P_{\min }}
$$

The values of the effective stress intensity factor range, $\Delta K_{\text {eff }}$, are given by the expression:

$$
\Delta K_{\mathrm{eff}}=K_{\mathrm{max}}-K_{\mathrm{op}}=U \Delta K
$$

During all the tests, the crack path at the specimen surface was carefully observed using an optical microscope. The fracture surfaces were observed in a Philips XL30 scanning electron microscope.

\section{Results and discussion}

\subsection{Typical transient behaviour and periodicity effect of single overloads}

The effect of periodically applied overloads for several numbers of baseline cycles between overloads, $n_{\mathrm{BL}}$, can be seen in Fig. 2. In Fig. 2(a), the crack length is plotted against the number of cycles, and Fig. 2(b) presents the correspondent crack growth rate against $\Delta K$. The behaviour under constant amplitude loading and for a single peak overload are superimposed for comparison.

For remotely spaced overloads $\left(n_{\mathrm{BL}} \geq 100\right.$ cycles) crack retardation and a corresponding decrease of $\mathrm{d} a / \mathrm{d} N$ relatively to constant amplitude loading are observed. As depicted in Fig. 2(a) the crack only reaches $10 \mathrm{~mm}$ length after more 80, 200 and $300 \%$ for, respectively, 100, 1000 and 10,000 intermediate baseline cycles, than those elapsed under constant amplitude loading to achieve the same crack length. Therefore, the longer the spacing $n_{\mathrm{BL}}$ between overloads the more severe retardation is produced. Moreover, the retardation of crack growth is always greater for periodic overloads applied with $n_{\mathrm{BL}} \geq 100$ cycles than for the equivalent single peak overload.

It is important to notice that maximum retardation occurred when tensile overloads were applied at a periodicity which was near the number of cycles associated to the minimum $\mathrm{d} a / \mathrm{d} N$ value attained for the single overload (11,600 cycles). Similar results, where obtained by Vardar and Yildirim [8] in 7075-T6 aluminium alloy, were maximum 

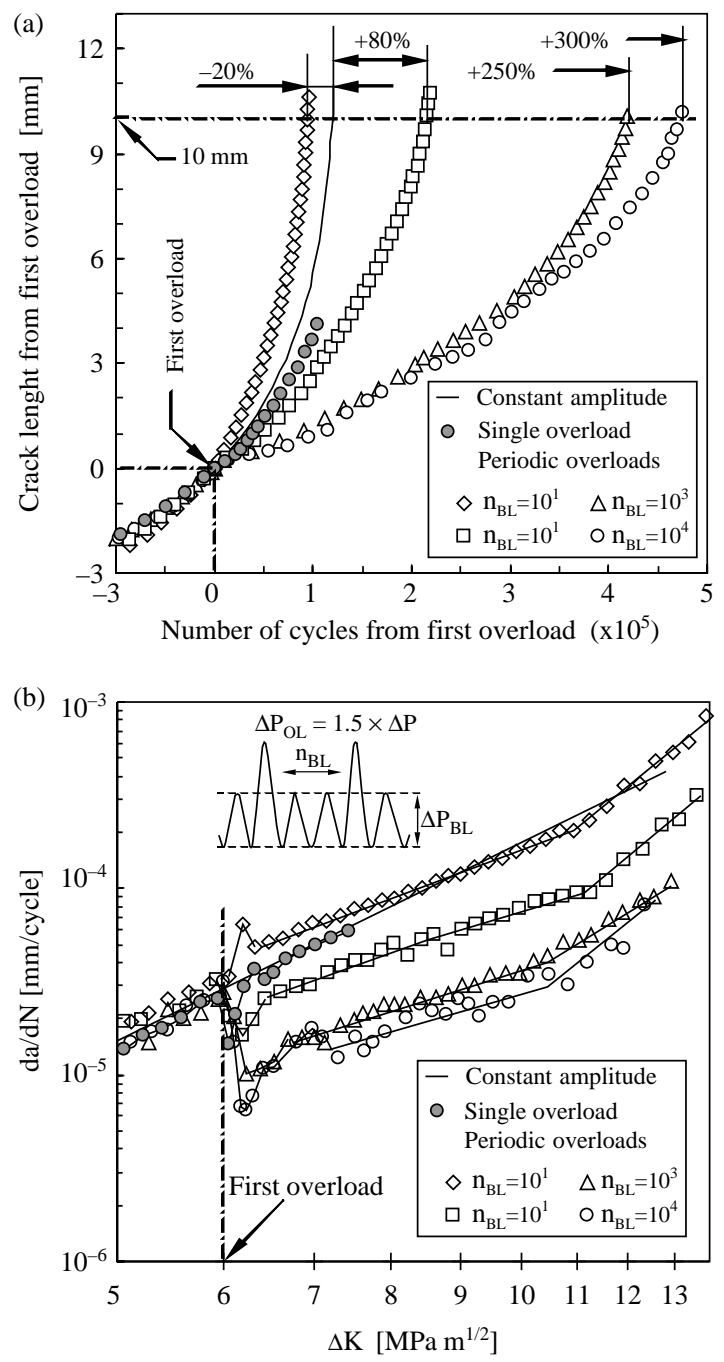

Fig. 2. Effect of the spacing between overloads, $R=0.05$ : (a) $a$ versus $N$; (b) $\mathrm{d} a / \mathrm{d} N$ versus $\Delta K$.

retardation was achieved when the spacing between overloads was half the number of cycles of the retarded growth induced by the single overload.

In contrast, the results for more frequently applied overloads ( $n_{\mathrm{BL}}=10$ cycles) present crack acceleration relatively to constant amplitude loading. For this loading condition, the crack length reached $10 \mathrm{~mm}$ after less 25,402 cycles than under constant amplitude loading, representing a fatigue life decrease of approximately $20 \%$.

An interesting feature that can be seen in Fig. 2(b) is that after application of the first overload the crack growth rate exhibits three distinct stages. Initially, a retardation period identical to that induced by a single peak overload [3-5] is observed for less frequently 
applied overloads. For overloads applied each 10 baseline cycles this initial stage is similar to the one generally observed after an underload $[10,11]$. The subsequent crack growth rate increases in a stable manner. Finally, for $\Delta K$ values above approximately $10.5 \mathrm{MPa} \mathrm{m}^{1 / 2}$ the crack growth rate increases more rapidly.

During the decreasing crack growth rate stage, the minimum crack growth rate value was attained only after approximately $29,000,38,000$ and 55,000 cycles for $n_{\mathrm{BL}}=100$, 1000 and 10,000, respectively. Furthermore, the initial retardation period persisted for several thousand cycles, approximately 52,000, 112,000 and 125,000 cycles for 100, 1000 and 10,000 intermediate baseline cycles, respectively. These values are significantly higher then those due to an equivalent single overload, respectively, 11,600 and 33,700 cycles, indicating a strong interaction between overloads in the beginning of their application. This interaction will induce progressively lower transient crack growth rates as indeed observed.

The initial retardation period persisted during approximately $1 \mathrm{~mm}$ for all the less frequently applied overloads $\left(n_{\mathrm{BL}} \geq 100\right)$, which curiously equals the single overload affected crack length $(0.99 \mathrm{~mm})$. This stage includes the minimum crack growth rate which was achieved at approximately $0.35 \mathrm{~mm}$ for all $n_{\mathrm{BL}} \geq 100$. This crack increment represents approximately $1 / 3$ of the equivalent single overload affected crack length.

Fig. 2(b) shows clearly that during the stable crack growth rate stage crack growth retardation increases with $\Delta K$ under remotely spaced overloads $\left(n_{\mathrm{BL}} \geq 100\right)$. Moreover, as observed in similar tests performed by Iwasaki et al. [9] in SM50B steel and by Ohrloff et al. [10] in 2024-T6 and 2091-T8 aluminium alloys, also in AlMgSi1-T6 aluminium alloy, the crack growth acceleration phenomenon observed under too closely spaced overloads decreases with $\Delta K$. During this phase, the acceleration phenomenon changes even to crack growth retardation for $\Delta K$ values above approximately $10 \mathrm{MPa} \mathrm{m}^{1 / 2}$. This is not surprising because the monotonic plastic zone produced by the overloads increases with $\Delta K$.

Both the acceleration decrease as well as the retardation increase can be clearly seen in Table 6 . This table presents the number of delay cycles, $N_{\mathrm{D}}$, at several crack lengths from the first overload, $a-a_{\mathrm{O}}$, and, consequently, at different $\Delta K$ values. $N_{\mathrm{D}}$, is the difference between the number of cycles at which the reference crack length is achieved and the number of cycles that would occur for the same crack length under constant amplitude baseline loading, $N_{\mathrm{CA}}$. For $n_{\mathrm{BL}}=10$, less $26 \%$ load cycles relatively to baseline loading are needed in order to attain a crack increment of $3 \mathrm{~mm}$, while for $a-a_{\mathrm{O}}=10 \mathrm{~mm}$ that

Table 6

Periodicity effect under intermittent single overload loading sequences at $R=0.05$

\begin{tabular}{|c|c|c|c|c|c|c|c|c|c|}
\hline \multirow{3}{*}{$\begin{array}{l}a-a_{\mathrm{O}} \\
(\mathrm{mm})\end{array}$} & \multirow{3}{*}{$\begin{array}{l}N_{\mathrm{CA}} \\
\text { (cycles) }\end{array}$} & \multicolumn{8}{|c|}{ Spacing between successive single overloads, $n_{\mathrm{BL}}$ (cycles) } \\
\hline & & \multicolumn{2}{|l|}{10} & \multicolumn{2}{|l|}{100} & \multicolumn{2}{|l|}{1000} & \multicolumn{2}{|l|}{10,000} \\
\hline & & $\begin{array}{l}N_{\mathrm{D}} \\
\text { (cycles) }^{\mathrm{a}}\end{array}$ & $N_{\mathrm{D}} / N_{\mathrm{CA}}$ & $\begin{array}{l}N_{\mathrm{D}} \\
\text { (cycles) }\end{array}$ & $N_{\mathrm{D}} / N_{\mathrm{CA}}$ & $\begin{array}{l}N_{\mathrm{D}} \\
\text { (cycles) }\end{array}$ & $N_{\mathrm{D}} / N_{\mathrm{CA}}$ & $\begin{array}{l}N_{\mathrm{D}} \\
\text { (cycles) }\end{array}$ & $N_{\mathrm{D}} / N_{\mathrm{CA}}$ \\
\hline 3 & 72,897 & $-18,704$ & -0.26 & 39,709 & 0.54 & 13,9863 & 1.92 & 16,8959 & 2.32 \\
\hline 6 & 10,3084 & $-25,718$ & -0.25 & 67,032 & 0.65 & 24,5127 & 2.38 & 27,8226 & 2.70 \\
\hline 10 & 11,9751 & $-25,402$ & -0.21 & 96,531 & 0.81 & 29,9557 & 2.50 & 35,5837 & 2.97 \\
\hline
\end{tabular}

\footnotetext{
a The - sign indicates that the number of cycles for $n_{\mathrm{BL}}=10$ is lower than under the baseline loading.
} 
difference is only of $21 \%$. For $n_{\mathrm{BL}}=1000$, the crack length increment achieves $3 \mathrm{~mm}$ after $192 \% \times N_{\mathrm{CA}}$ cycles while for achieving $10 \mathrm{~mm}$ that increase is already of $250 \%$. For the other intermediate baseline cycles the same trend is observed.

\subsection{Stress ratio effect}

The effect of intermittent overloads at $R=0.4$ for 100 and 1000 baseline cycles are shown in Fig. 3. The corresponding results obtained for intermittent overloads at $R=0.05$ and under constant amplitude loading are also superimposed for comparison.

This figure shows that the crack retardation effect is lower at higher mean stress. For example, in order to attain a $6 \mathrm{~mm}$ crack length increment more 53,496 and 119,039 cycles are needed for 100 and 1000 intermediate baseline cycles, respectively, than those elapsed under constant amplitude loading at $R=0.4$. It is important to notice that these load cycles are lower then those obtained at $R=0.05$ to reach the same crack length (Table 6). However, at $R=0.4$ they correspond to a larger relative increment of crack growth: 115 and $257 \%$ for $n_{\mathrm{BL}}=100$ and 1000 , respectively.

\subsection{Crack closure}

The measured crack closure levels at $R=0.05$ are exhibited in Fig. 4 . The obtained data are plotted in terms of the normalized load ratio parameter, $U$, calculated by Eq. (2), against $\Delta K$. The acquisition of each load-displacement record was carried out approximately at half interval between successive overloads. Therefore, the depicted $U$ values have to be understood as the average closure level at each interval between successive overloads.

Fig. 4 shows that, except during a small range of $\Delta K$ following the first overload for $n_{\mathrm{BL}}=10$, the crack closure level for periodically applied overloads is always much higher

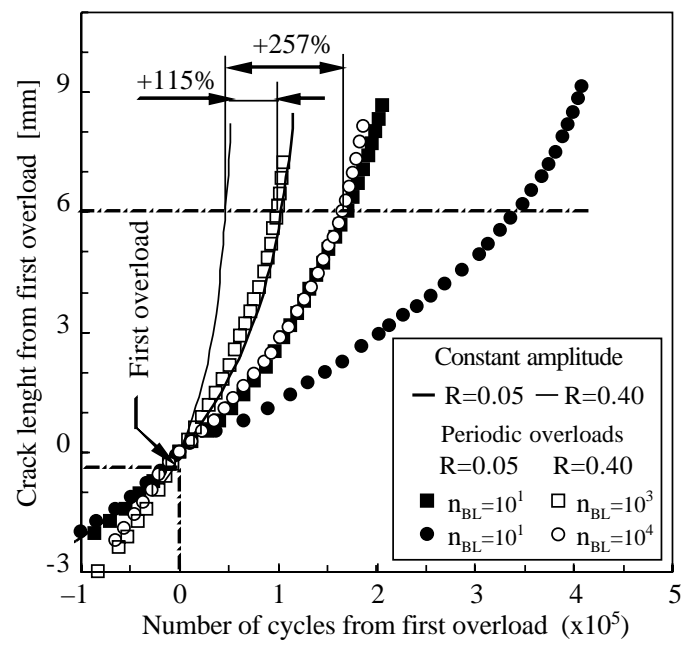

Fig. 3. Influence of stress ratio. 


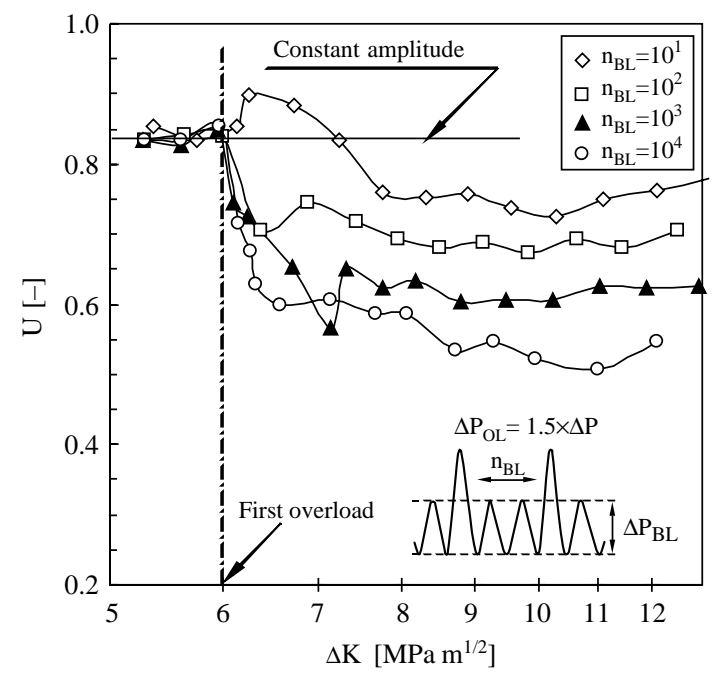

Fig. 4. Mean closure levels for periodic overloads, $R=0.05$.

than under constant amplitude loading. Generally the $U$ parameter decreases, i.e. the crack closure level increases with the number of intermediate baseline cycles.

Prior to the first overload the $U$ parameter at the constant amplitude baseline loading level is relatively stable. Upon application of the first overload the crack closure level increases quickly for remotely spaced overloads and decreases slightly for closely spaced overloads, followed by a slow increase or even certain stabilization. There is also a small decrease of the crack closure level at $\Delta K$ values above approximately $10 \mathrm{MPa} \mathrm{m}^{1 / 2}$. The minimum value of $U$ attained was $0.73,0.67,0.57$ and 0.51 for $10,100,1000$ and 10,000 intermediate baseline cycles, respectively, corresponding to a decrease of approximately 13, 20, 32 and 39\% relatively to the $U$ baseline level observed in constant amplitude loading. The crack closure levels measured at 1000 and 10,000 intermediated baseline cycles are closely to each other as also observed for the corresponding crack growth rates (Fig. 2). Therefore, it becomes obvious that the crack closure data show basically the same trend as the corresponding experimentally observed crack growth rate response. Moreover, the influence of the overload periodicity in the crack growth rate is in agreement with the different closure levels.

As reported for single overloads in the analysed alloy [6,7] the observed crack growth trends under periodic overloads are consistent with the plasticity-induced crack closure phenomenon. Each overload produces higher monotonic plastic zone than the baseline loading. As the crack grows into the compressive residual stress field formed by the overload cycle it encounters increased levels of plasticity that induce near tip closure. This results in an increase of the crack opening load which implies a reduction of the minimum effective driving force behind the crack. The corresponding crack growth rates must, therefore, be lower as indeed observed.

As discussed earlier, the retardation effect is more pronounced when overloads were applied at a periodicity near the number of cycles at which the minimum value of the crack 
growth rate for the equivalent single overload was reached. When the overload is applied still in the period when crack growth rates are decreasing it suspends the crack delay due to the previous overload, reducing in this way the retardation effect.

The crack closure level measured for closely spaced overloads $\left(n_{\mathrm{BL}}=10\right)$ is higher than for the baseline loading only in the $\Delta K$ range between 6 and $7 \mathrm{MPa} \mathrm{m}{ }^{1 / 2}$. However, during the phase of stable crack growth the crack propagation rate is higher than under constant amplitude loading until approximately $9 \mathrm{MPa} \mathrm{m}^{1 / 2}$ as showed in Fig. 2(b). This apparent contradiction, i.e. simultaneous higher crack closure level and crack growth rate than in constant amplitude loading, is not necessarily in disagreement with the plasticity-induced closure argument, because too closely spaced overloads lead to acceleration rather than retardation since crack jump at each overload greatly exceeds the retardation in the subsequent few baseline cycles.

The crack growth rates inferred directly from the experimental closure measurements depicted in Fig. 4 and the characteristic $\mathrm{d} a / \mathrm{d} N$ versus $\Delta K_{\text {eff }}$ relation of the material are compared with the experimental crack growth rates in Fig. 5. The characteristic $\mathrm{d} a / \mathrm{d} N$ versus $\Delta K_{\text {eff }}$ relation of the material, which was determined in previous work [6], is given by:

$$
\frac{\mathrm{d} a}{\mathrm{~d} N}=1.23 \times 10^{-7}\left(\Delta K_{\mathrm{eff}}\right)^{3.39}, \quad 2.5 \leq \Delta K_{\mathrm{eff}} \leq 12
$$

where $\mathrm{d} a / \mathrm{d} N$ and $\Delta K_{\text {eff }}$ are in $\mathrm{mm} /$ cycle and $\mathrm{MPa} \mathrm{m}^{1 / 2}$, respectively.

In spite of the crack closure phenomenon being able to correlate the majority of the crack growth transients and also the periodicity effect, the inferred and measured crack growth rates show good agreement only for the loading sequence containing overloads applied each 100 intermediate baseline cycles. For closely spaced overloads $\left(n_{\mathrm{BL}}=10\right)$

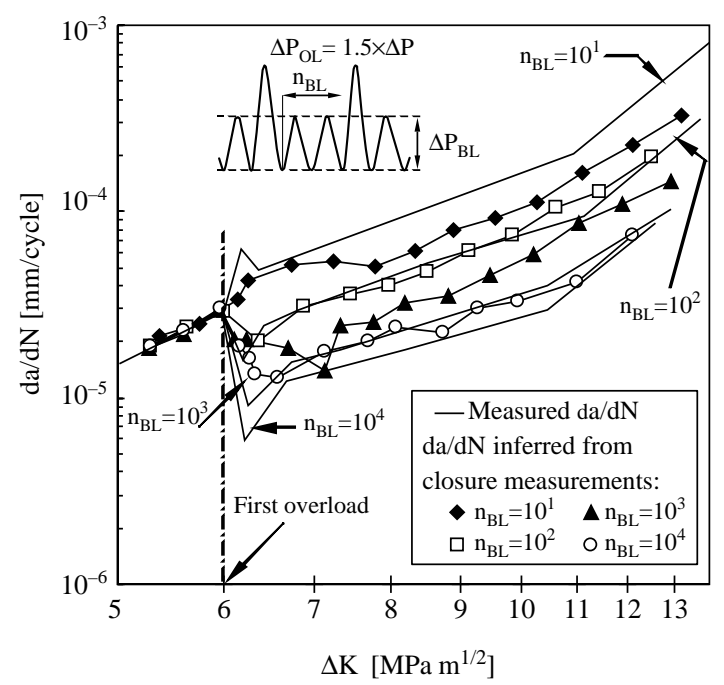

Fig. 5. Comparison between predicted from closure measurements and experimental crack growth rates. 
the predicted crack growth rates are lower and for $n_{\mathrm{BL}}=1000$ and 10,000 higher than experimental ones. Furthermore, the small crack closure reduction observed for high $\Delta K$ values does not permit, by it self, the explanation of the crack growth rate quick increase above $10.5 \mathrm{MPa} \mathrm{m}^{1 / 2}$.

As already mentioned, the crack closure levels presented in Fig. 4 are mean values. Therefore, the discrepancy between inferred and experimental crack growth rates reinforces the idea that closure based damage models must perform a cycle by cycle analysis in order to achieve warrantable predictions. In addition at high $\Delta K$ values, the crack growth due to each overload cycle is more significant than the expected rise of the retardation effect with $\Delta K$ due to the increase of the monotonic plastic zone induced by the overload. This behaviour is in accordance with the experimental results of Dawicke [15] and Phillips [16], where diminish of the crack growth retardation effect was observed for overloads with very high magnitudes.

\subsection{Analysis of the fatigued fracture surfaces}

Fig. 6 shows the typical features of the periodic single overload fatigued fracture surfaces. This figure corresponds to the test performed under the loading sequence with one overload applied each 10,000 baseline cycles at $R=0.05$. The images presented were obtained at the position close to the centre of the specimens. Fig. 6(a) is a low magnification image of the fatigued fracture surface, while Fig. 6(b) and (c) are high magnification images of the regions before and after an overload reapplication, respectively. Finally, Fig. 6(d) illustrates some details of the fatigue fracture surface during an overload cycle at high $\Delta K$ levels.

Fig. 6(a) $\left(\Delta K=7.5 \mathrm{MPa} \mathrm{m}{ }^{1 / 2}, \mathrm{~d} a / \mathrm{d} N=1.4 \times 10^{-5} \mathrm{~mm} /\right.$ cycle $)$ corresponds to the stable crack growth rate stage following the first overload. This figure shows a marking line after each overload cycle similar to that observed following single peak overloads [7]. As expected, the spacing between these markings increases with crack length because the crack growth rate increases with $\Delta K$.

Typical fatigue fracture surfaces of AlMgSi1-T6 alloy have a relatively chaotic wavy appearance and the fracture path did not seem the result from a single mechanism of fracture (Fig. 6(b)). The crack propagates on multiple plateaus that are at different elevations with respect to each other. The plateaus are joined either by tear ridges or walls. These relatively smooth areas consisted predominantly of transgranular fatigue propagation containing fairly well-developed striations with evidence of some secondary cracking and widely dispersed microvoid formation around second-phase particles. These observations are consistent with those reported for similar alloys [17].

It can be clearly seen, by comparison between Fig. 6(b) and (c), that the pre-overload fracture region has more irregular surface topography than the region after the overload reapplication. Furthermore, Fig. 6(d) shows that the post-overload region exhibits intense smeared zones (marked by arrows) denoting increased contact between crack faces. These observations provide good evidence for the enhancement of crack closure immediately after each overload reapplication.

Fig. 6(b) $\left(\Delta K=12.5 \mathrm{MPa} \mathrm{m}^{1 / 2}, \mathrm{~d} a / \mathrm{d} N=8.1 \times 10^{-5} \mathrm{~mm} /\right.$ cycle $)$ also shows an intense formation of dimples at high $\Delta K$ values due to the strong plastic deformation during 
the overload cycle. This microvoid formation will necessarily imply an increase of crack growth rates following each overload cycle. This observation is in accordance with the reasoning that at high $\Delta K$ values the crack growth due to each overload cycle is more significant than the increase of the retardation effect with $\Delta K$.

\subsection{Periodic multiple overloads}

The results obtained under periodic multiple overloads are shown in Fig. 7, plotted as the crack length against the number of cycles. The $a-N$ curves obtained under constant amplitude loading corresponding to the higher and lower load levels used in the tests are superimposed for comparison. In addition the crack growth behaviour under the loading sequence containing periodic single overloads applied each 1000 cycles at $R=0.05$ is also represented in this figure.
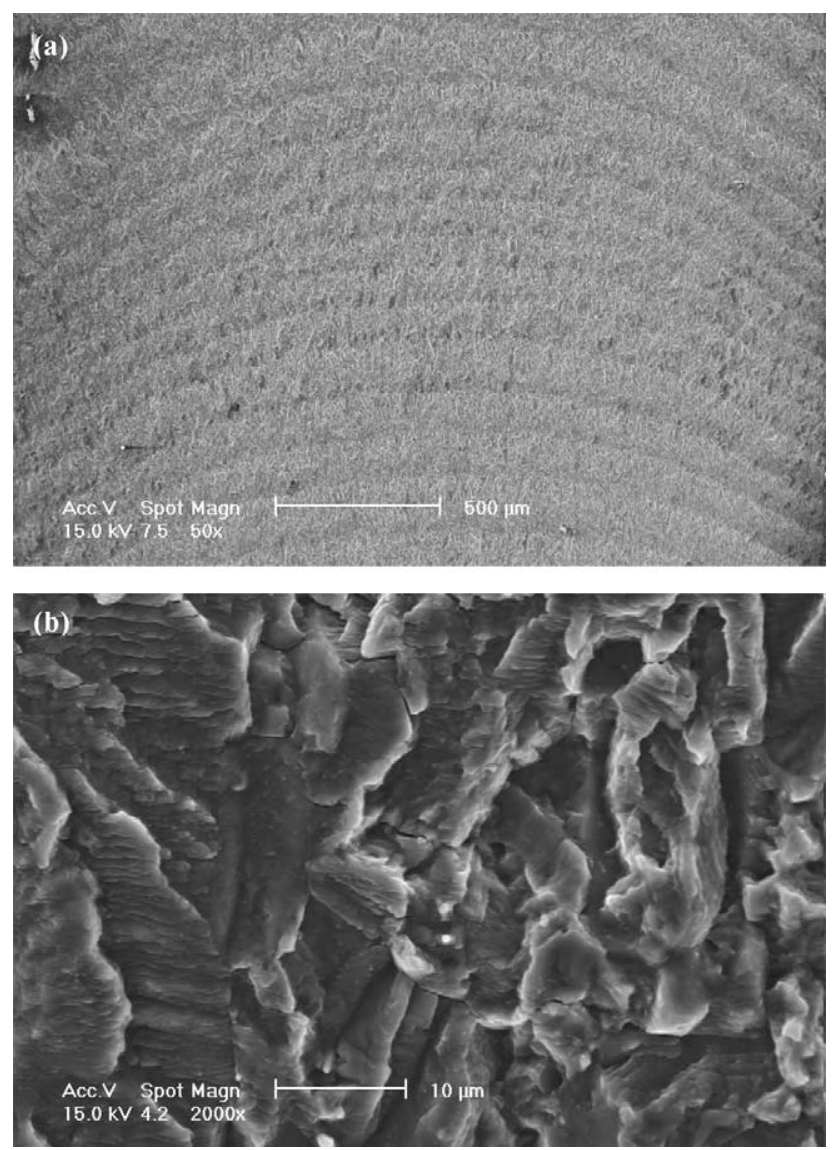

Fig. 6. SEM images of fatigued fracture surfaces, $R=0.05$ and $n_{\mathrm{BL}}=10,000$ : (a) marking lines, (b) region before an overload reapplication, (c) post-overload reapplication zone, (d) effect of the overload cycle at high $\Delta K$ values. 

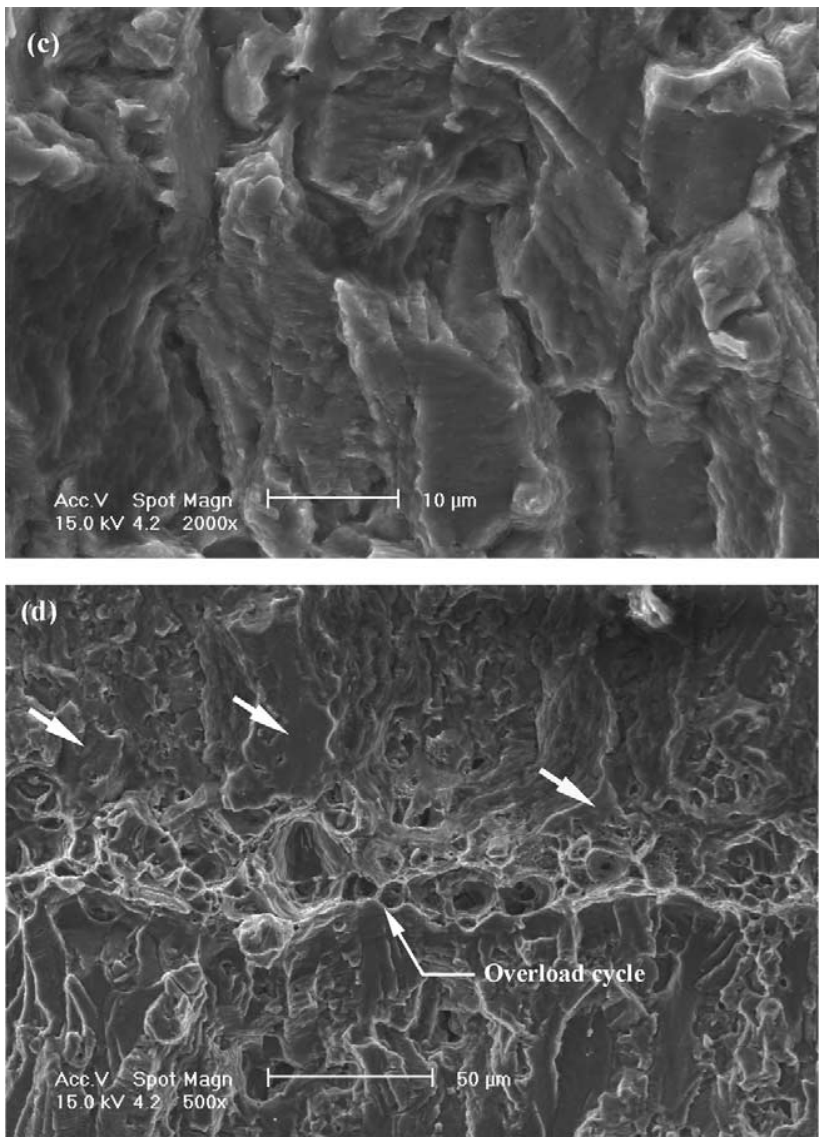

Fig. 6 (continued)

The periodic multiple overload $a-N$ curves are located between constant amplitude loading results obtained for the higher and lower load levels. The loading sequence with only one periodic overload presented crack retardation while the loading sequences (a) and (c), with the same periodicity (1000 cycles), show crack acceleration relatively to constant amplitude baseline level, i.e. to lower load range level. Similar results were obtained by Iwasaki et al. [9]. These authors observed the enhancement of the crack retardation effect for loading sequences containing until 100 overloads in each block $\left(n_{\mathrm{BL}}=10,000\right)$, however 1000 overloads applied each 10,000 baseline cycles lead to crack acceleration.

Crack acceleration is more pronounced for loading sequence (a) than for (c), suggesting an increase of crack acceleration with the number of overloads in each block. The equivalent stress range, $\Delta \sigma_{\text {eq }}$, for each loading sequence can be obtained by the following simple expression

$$
\Delta \sigma_{\mathrm{eq}}=\frac{\sum \Delta \sigma_{i} N_{i}}{\sum N_{i}}
$$




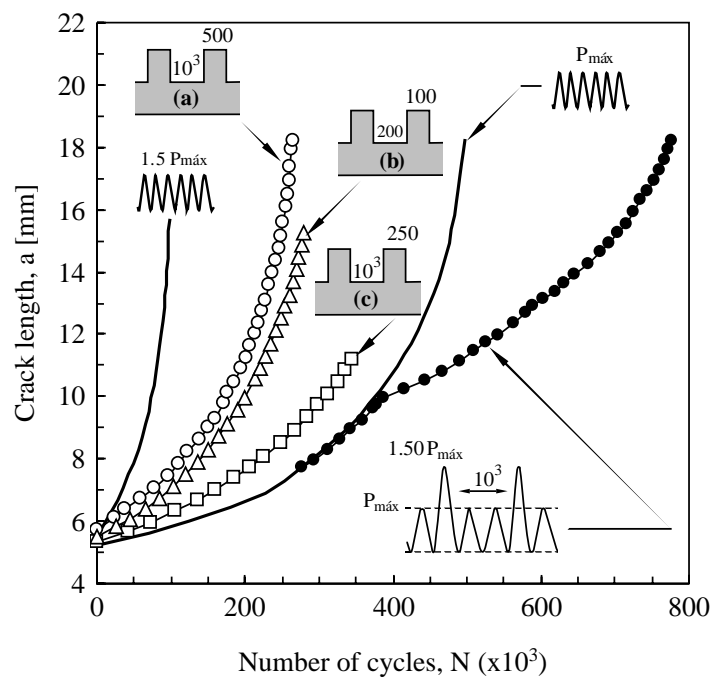

Fig. 7. Crack growth under periodic multiple overloads.

where $\Delta \sigma_{i}$ and $N_{i}$ are, respectively, the stress range and the number of cycles of each load level $i$ that compose the period of the loading sequence. For loading sequence (a) $\Delta \sigma_{\text {eq }}=$ 33.5 MPa while for sequence (c) $\Delta \sigma_{\text {eq }}=31.5 \mathrm{MPa}$ in agreement with the accelerated crack growth observed for the first loading sequence. However, sequences (a) and (b) have the same $\Delta \sigma_{\text {eq }}$ value and show simultaneously slightly different $a-N$ curves, clearly suggesting the load interaction effects.

The differences between these two loading sequences can, however, be easily explained considering the behaviour relatively to the higher load level constant amplitude loading. Sequence (b) has 5 times more load variations than sequence (a) for equal number of load cycles. It is well established that the retardation effect induced by load step-down is much more pronounced than crack growth acceleration due to load step-up [2]. Therefore, enhanced crack retardation relatively to the higher load level constant amplitude loading should be expected for loading sequence (b) as indeed observed.

\subsection{Periodic three-level loading sequences}

Fig. 8 shows $a-N$ curves obtained under periodic three-level loading sequences. The crack growth data obtained under constant amplitude loading corresponding to higher and intermediate load levels used in the tests are superimposed for comparison.

This figure shows that the $a-N$ curves corresponding to the periodic three-level loading sequences are comprised between constant amplitude loading crack growth data obtained for higher and intermediate load levels. Crack growth under loading sequence (a) is slightly slower than under sequence (b). Additionally, crack growth under loading sequence (c) is significantly slower than under sequence (b) (the number of load cycles at $a=18 \mathrm{~mm}$ is $14 \%$ higher for loading sequence (c)). 


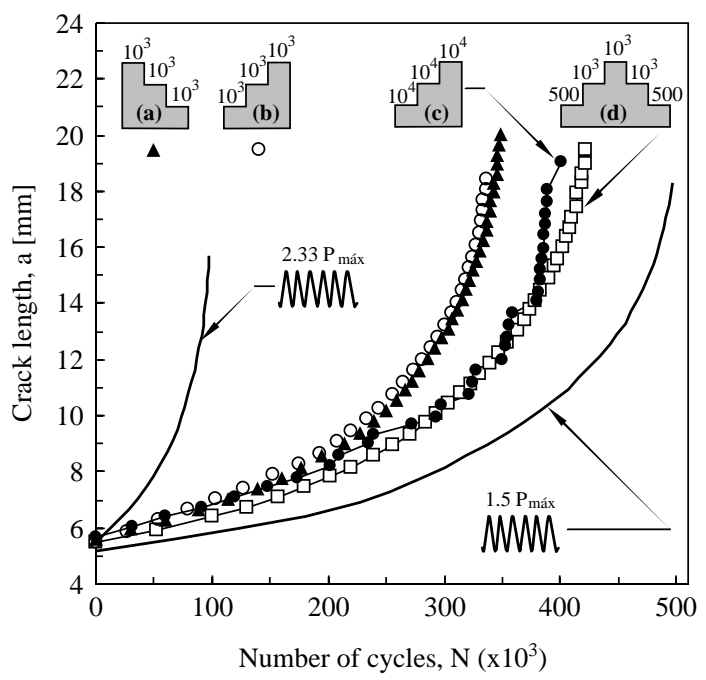

Fig. 8. Crack growth under periodic three-level loading sequences.

Trends mentioned above, i.e. enhanced crack growth retardation under sequences with decreasing load levels in comparison to increasing ones, as well as under loading sequences with extended periodicity, are in agreement with the experimental results obtained by Schijve [18] for 2024-T3 aluminium alloy. The slower crack growth observed under loading sequence (c) in comparison to (b) suggests larger load sequence effects for test performed with longer return period and reemphasizes the need of using loading sequences with relatively short periods when simulating load service spectrums in order to obtain safe life predictions.

The more retarded crack growth was achieved under loading sequence (d). It is important to notice that loading sequences (a)-(c) have the same $\Delta \sigma_{\text {eq }}$ value (31.2 $\mathrm{MPa}$ ), while for loading sequence (d) this value is slightly lower (30.7 MPa). Furthermore, this last sequence has more load variations in one period than all other. Therefore, the lower $\Delta \sigma_{\text {eq }}$ associated to the eventual higher load interaction due to loading complexity can probably explain the slower crack growth observed for this loading sequence.

\section{Conclusions}

A reapplication of an overload after a period of baseline cycling reactivates mechanisms which lead to fatigue crack growth retardation. However, its delay effect is reduced when the overload is reapplied still in the phase of descending fatigue crack growth rates, because it will interrupt the crack retardation process produced by the preceding overload. Therefore, the most effective retardation is obtained when the period between overloads is sufficiently long to cause the crack growth rate to reach a minimum. Additionally, at low $\Delta K$ baseline levels when the overload reapplication occurs still during the acceleration stage associated with the prior overload the overall effect can even be 
acceleration in fatigue crack growth rates. Crack retardation increases with overload periodicity and decreases with stress ratio increase.

The influence of single overload spacing is in agreement with the different closure levels. In spite of some discrepancy, attributed to the quick change of the closure levels, it becomes obvious that plasticity-induced crack closure plays an important role on the observed load interaction effects.

Loading sequences containing periodic blocks with more than 250 overloads resulted in accelerated crack growth. Furthermore, an increase of crack acceleration with the number of overloads in each block was observed. For periodic three-level loading sequences a longer return period resulted in enhanced crack retardation relatively to a shorter return period, thus indicating much larger load sequence effects for test performed with long periods.

\section{Acknowledgements}

The authors would like to acknowledge POCTI programme, project 1999/EME/32984, for funding the work reported.

\section{References}

[1] Ward-Close CM, Blom AF, Richie RO. Mechanisms associated with transient fatigue crack growth under variable amplitude loading: an experimental and numerical study. Eng Fract Mech 1989;32(4):613-38.

[2] Ng'Ang'a SP, James MN. Variable amplitude loading in En8 (080M40) steel: a detailed experimental study of crack growth. Fatigue Fract Eng Mater Struct 1996;19:207-16.

[3] Shercliff HR, Fleck NA. Effect of specimen geometry on fatigue crack growth in plane strain-II. Overload response. Fatigue Fract Eng Mater Struct 1990;13:297-310.

[4] Shin CS, Hsu SH. On the mechanisms and behaviour of overload retardation in AISI 304 stainless steel. Int J Fatigue 1993; 15:181-92.

[5] Shuter DM, Geary W. Some aspects of fatigue crack growth retardation behaviour following tensile overloads in a structural steel. Fatigue Fract Eng Mater Struct 1996;19:185-99.

[6] Borrego LP, Ferreira JM, Costa JM. Fatigue crack growth and crack closure in an AlMgSi alloy. Fatigue Fract Eng Mater Struct 2001;24:255-65.

[7] Borrego LP, Ferreira JM, Pinho da Cruz JM, Costa JM. Evaluation of overload effects on fatigue crack growth and closure. Eng Fract Mech 2003;70:1379-97.

[8] Vardar O, Yildirim N. Crack growth retardation due to intermittent overloads. Int J Fatigue 1990;12:283-7.

[9] Iwasaki T, Katoh A, Kawahara M. Fatigue Crack growth under random loading. Naval Arch Ocean Eng (Jpn) 1982;20:194-216.

[10] Ohrloff N, Gysler A, Lütjering G. Fatigue crack propagation behaviour under variable amplitude loading. In: Petit J, Davidson DL, Suresh S, Rabbe P, editors. Fatigue crack growth under variable amplitude loading. New York: Elsevier; 1988. p. 24-34.

[11] Zhang S, Marissen K, Schulte K, Trautmann KH, Nowack H, Schijve J. Crack propagation studies on Al 7475 on the basis of constant amplitude and selective variable amplitude loading histories. Fatigue Fract Eng Mater Struct 1987;1:315-32.

[12] Fleck NA. Fatigue crack growth due to periodic underloads and overloads. Acta Metal 1985;33:1339-54.

[13] American Society for Testing and Materials. Standard test method for measurements of fatigue crack growth rates. Annual Book of ASTM Standards, Volume 03.01, ASTM E 647; 1995. p. 562-598. 
[14] Allison JE, Ku RC, Pompetzki MA. A comparison of measurement methods and numerical procedures for the experimental characterization of fatigue crack closure. In: Newman Jr JC, Elber W, editors. Mechanics of fatigue crack closure, ASTM STP 982. Philadelphia, USA: American society for testing and materials; 1988. p. 171-85.

[15] Dawicke DS. Overload and underload effects on the fatigue crack growth behavior of the 2024-T3 aluminum alloy. Nasa Technical Contractor Report, NASA/CR-201668. National Aeronautics and Space Administration, Langley Research Center, Hampton, Virginia, USA; 1997. p. 1-9.

[16] Phillips EP. Periodic overload and transport spectrum fatigue crack growth tests of Ti62222STA and A12024T3 sheet. Nasa Technical Memorandum, NASA/TM-1999-208995. National Aeronautics and Space Administration, Langley Research Center, Hampton, Virginia, USA; 1999. p. 1-38.

[17] Bhandarkar MD, Lisagor WB. Metallurgical characterization of the fracture of aluminum alloys. In: Strauss BM, Cullen WH, editors. Fractography in Failure Analysis, ASTM STP 645. Philadelphia: American Society for Testing and Materials; 1978. p. 176-209.

[18] Schijve J. Effect of load sequences on crack propagation under random and program loading. Eng Fract Mech 1973;5:269-80. 